\title{
Risky Sexual Behaviour among Sexually Active Never Married Ghanaian Women: A Latent Class Analysis (LCA)
}

\author{
Kamil Fuseini ${ }^{1}$ \\ Population Training and Research Unit, Faculty of Human and Social \\ Sciences, North-West University (Mafikeng Campus), Mafikeng, South \\ Africa
}

\section{Abstract}

This paper examined risky sexual behaviour patterns among sexually active never married Ghanaian women using the 2008 GDHS data. The LCA technique was utilised to identify categories of women based on their risky sexual behaviours. Age at first sex, multiple sexual partnerships, condom use at first and last sexual intercourse, lifetime sexual partners and alcohol consumption at last sex were used for the categorisation. Preferably, a 3-class model that reflected "low risk takers," "risk takers" and "high risk takers" was selected. Generally, the sexual behaviours followed similar patterns. For instance, the conditional probability for unprotected sex at first sexual intercourse was 0.34 in Class I-“low risk takers", 0.84 in Class 2-“risk takers" and 0.86 in Class 3-"high risk takers". Latent multinomial logistic regression model was used to examine the predictors of class membership. Older women were more likely to be classified in both the "risk takers" and "high risk takers" classes.

Keywords: Never married, risky sexual behaviour, Ghana

\section{Résumé}

Ce document examiné les modèles de comportements sexuels à risque chez les sexuellement active jamais mariée ghanéennes en utilisant les données de GDH de 2008. La technique de la LCA a été utilisée pour identifier des catégories de femmes basées sur leurs comportements sexuels risqués. Âge au premier sexe, multiples partenariats sexuels, l'utilisation du préservatif au premier et dernier rapport sexuel et la durée de vie des partenaires sexuels ont été utilisés pour la catégorisation. De préférence, un modèle de classe 3 qui reflète les " preneurs de risque faible ", "preneurs de risques " et " preneurs de risques élevés " a été

\footnotetext{
${ }^{1}$ Correspondence:
}

Email: fuseinikamil@gmail.com or 25163175@nwu.ac.za

Address: Private Bag X2046, Mmabatho, 2735 Mafikeng South Africa

Tel: +27183892588

Fax: +27183892228 
sélectionné. Généralement, les comportements sexuels suivis des profils similaires. Par exemple, la probabilité conditionnelle pour les rapports sexuels non protégés au premier rapport sexuel a été 0,34 en classe $\mathrm{I}-$-« preneurs de risques faibles », 0,84 à la classe 2 -« preneurs de risques » et 0,86 en classe 3 -« preneurs de risques élevés ". Modèle de régression logistique multinomiale latente a été utilisé pour examiner les prédicteurs de l'adhésion de la classe. Les femmes plus âgées étaient plus susceptibles d'être classés dans les classes "preneurs de risques élevés » et "preneurs de risques »

Mots-clés: Comportement sexuel non marié, risqué, Ghana

\section{Introduction}

Risky sexual behaviours are still a major challenge across the world, especially in sub-Saharan Africa where HIV prevalence as well as other Sexually Transmitted Infections (STIs) are still of great concern. Risky sexual behaviours such as unprotected sexual encounter, early age at sexual activity, alcohol abuse during sexual intercourse and multiple sexual partners exposes individuals to the risk of STIs, such as HIV infection and further compounds the burden of disease (Akwara, Fosu, Govindasamy, Alayón \& Hyslop, 2005).

Women are more susceptible to STls than men, which is mostly attributed to their biological make up. Their susceptibility is further heightened by social, cultural, economic and gender inequities where women are not able to negotiate for safe sex and in most cases rely on their partners for protection. The onus of correct and consistent use of condoms and other safe sex practices rests with the male partner, which exacerbates women's exposure to STls (Mturi \& Gaearwe, 20I4; Sachdeva \& Wanchu, 2006). In addition, some studies suggest that of the unmarried women, never married African women are more exposed to the risk of STls compared to their married counterparts (Chao et al., 1994; Nunn, Kengeya-Kayondo, Malamba, Seeley \& Mulder, 1994). Further, analyses of data in Ghana and Kenya showed that HIV infection per year of exposure is higher before than after first marriage. Often what accounts for the higher risk among never married women is the average period between age at first sexual intercourse and first marriage (Bongaarts, 2007).

Previous studies on sexual behaviours in sub-Saharan Africa including Ghana often concentrate on variable-centred analysis techniques, which presume that the study population is homogeneous with regard to how the underpinning factors influence risky sexual behaviours. Thus, these studies have provided a better understanding of the factors related to risky sexual behaviours (Akwara et al., 2005; Asante, Meyer-Weitz, \& Petersen, 2014; Doku, 2012; Halpern-Felsher, Millstein, \& Ellen, 1996; Karim, Magnani, Morgan, \& Bond, 2003; Nunn et al., 1994; Wojcicki, 2005). However, there is little empirical evidence on the subgroups of 
women based on their sexual behaviour patterns in Ghana, even though this approach has been used to examine sexual behaviour patterns elsewhere (Connell, Gilreath \& Hansen, 2009).

Subgroup analysis which is personcentred, identifies different and distinct patterns of behaviour in the wider population-this analytic technique has the potential to help develop tailored intervention efforts to get at the needs of specific subgroups in the population (Lanza, Collins, Lemmon, \& Schafer, 2007; Lanza \& Rhoades, 2013). A risk-focused approach will provide an efficient basis for targeting individuals who are at risk and trying to mitigate risky sexual behaviours by designing tailored programmes (Lanza \& Rhoades, 20I3). Thus, the present study seeks to derive a categorisation of sexually active never married Ghanaian women in order to describe and analyse their risky sexual behaviour patterns.

\section{Methods}

\section{Data}

This paper utilises data from the 2008 Ghana Demographic and Health Survey (GDHS), which is a nationally representative sample survey that uses standardised multistage cluster sampling. The GDHS methodology has been described in detail elsewhere (GSS, GHS \& ICF Macro, 2009). The 2008 GDHS data is not self-weighted. However, weights are included within the 2008 GDHS dataset and are utilized in the present analysis. The data is weighted taking into account the complex survey design, using the 'svyset' commands in Stata. This corrects for nonresponse and ensures representativeness across Ghana. For the purpose of this study, of all the women 15-49 years who were interviewed, only sexually active never married Ghanaian women were included in the analysis (the analytical sample for this paper is 775-weighted total is 819 ).

\section{Variables selected for LCA}

LCA is a statistical technique used to classify cases into a set of distinct and mutually exclusive latent subgroups of individuals that is based on their answers to a number of categorical questions (Lanza et al., 2007). In this paper, six (6) variables: I) age at first sexual intercourse; 2) condom use at first sexual intercourse; 3 ) condom use at last intercourse; 4) number of sexual partners (other than spouse) in the last 12 months; 5) total lifetime number of sexual partners and 6) alcohol consumption last time had sex were used for the LCA modelling. These variables were utilised in identifying the set of discrete and mutually exclusive risky sexual behaviour patterns among sexually active never married Ghanaian women.

A woman was considered to be engaged in risky sexual behaviour if she had sexual intercourse before age 16 , this is the age at which a female can consent for sex in Ghana (women are usually considered vulnerable below that age) (also see Madise, Zulu, \& Ciera, 2007). In addition, if a condom was not used at first sexual encounter, and if a condom was not used at last sexual encounter, having had sexual intercourse with other sexual partners, and having more than three lifetime sexual partners were regarded to be engaged in risky sexual behaviour. Lastly, women were considered to be involved in risky 
sexual behaviour if alcohol was consumed during their last sexual intercourse.

\section{Independent variables}

Based on the literature (Connell et al., 2009; Doku, 2012; Karim et al., 2003), a number of independent variables were selected to see how they varied by the latent classes (that is the class associations). The variables selected were; age which was treated as a continuous variable, education was treated as a categorical variable (coded into; 0 - below secondary education and I - secondary education or higher). Religion was treated as a categorical variable (coded as; I Christian, 2 - Muslim and 3 - Other) and type of place of residence was treated as a categorical variable (coded as; 0 - urban and I- rural). In addition, economic status was measured using women's participation in wage earning labour, since wealth quintile does not necessarily reflect economic status of an individual but the household. Hence it was treated as a categorical variable (coded as; 0 - earning wages and I - not earning wages). Knowledge of HIV prevention combined three variables: I) reduce risk of getting AIDS: do not have sex at all; 2) reduce risk of getting AIDS: always use condoms during sex; 3) reduce risk of getting AIDS: have I sex partner only. Each of the three variables were dummy coded into 0 wrong answer and I - correct answer. The three variables were then summed up to get knowledge of HIV prevention index ranging from 0 to 3 .

\section{Statistical analysis}

The LCA was applied to empirically examine risky sexual behaviour patterns among sexually active never married Ghanaian women. The LCA statistical technique can be used to empirically identify discrete latent variables from two or more observed categorical variables (Dewilde, 2004; Lanza \& Rhoades, 2013). The class an individual belongs is usually not known; however, it can be derived from a number of observed variables. The LCA technique makes it possible to get the probability of a person belonging to a latent class that is dependent on data. The individuals are categorised into mutually exclusive classes based on the individual respondent's posterior probabilities for class membership for a specific risky sexual behaviour profile (Lanza et al., 2007).

In this study, the LCA methodology allowed for the grouping of sexually active never married women into distinct risky sexual behaviour classes or groups (Class I-“low risk takers", Class 2-"risk takers" and Class 3-"high risk takers") and included in the analysis. The probability of a respondent being a member of a specific class is then estimated using the latent multinomial logistic regression model to predict class membership utilising the factors listed above under independent variables. The Stata plugin (version I.2) was used to implement the LCA procedures (Lanza, Dziak, Huang, Wagner \& Collison, 2015).

\section{Model selection}

A range of two to five latent classes was examined. A 2-class model was fitted first; this was then followed by successively increasing the number of classes to a maximum of 5-class model. How well each model fit the data were examined based on the $G^{2}$ statistic and when appropriate their 
corresponding degrees of freedom were also taking into consideration. In addition, the selection of the best fit model also took into consideration the information criteria-AIC, BIC, CAIC, and aBIC (Lanza et al., 2007).

\section{Statistical techniques}

After determining the latent classes, the chi-square test was utilised to examine the association between the identified classes and the selected independent variables. In addition, the One-Way Analysis of Variance procedure was used to determine whether there were any significant differences in the age of respondents and knowledge of HIV prevention across the 3 classes. To examine the predictors of class membership, the latent multinomial logistic regression model was utilised.

\section{Results}

\section{Descriptive statistics}

Table I shows frequency distributions of the variables utilised in this study. About a fifth $(19.50 \%)$ of the women had sexual intercourse before age 16 . About $76 \%$ of the women did not use condom at first sexual intercourse and $78 \%$ did not use condom at last sexual intercourse. A little more than seven in ten $(72.73 \%)$ had sexual intercourse with person(s) other than their partners' and approximately $7 \%$ had more than three lifetime sexual partners. About $5 \%$ consumed alcohol at last sexual intercourse.

A little less than a fifth (17.8I\%) of the women did not have secondary education or higher. Eighty four percent of the respondents were Christian, 12.53\% Muslim and less than 5\% (3.27\%) affiliated to other religions. A little more than three fifth $(62.45 \%)$ of the women were in urban areas and a little more than half $(52.46 \%)$ of the women were engaged in wage earning labour. Mean age of the women was 22.1 I years (range 15-49 years) and mean knowledge of HIV prevention was 2.46 (range 0-3).

\section{Table 1: Descriptive statistics}

\begin{tabular}{lclll}
\hline Variable & Code & Label & Frequency & Percent \\
\hline Indicators of latent class & & & & \\
Sexual intercourse after age I6 & I & No & 160 & 19.50 \\
& 2 & Yes & 659 & 80.50 \\
Sexual intercourse with only partner in & I & No & 596 & 72.73 \\
the last I2 months & 2 & Yes & 223 & 27.27 \\
& I & No & 620 & 75.74 \\
Condom used at first sexual intercourse & 2 & Yes & 199 & 24.26 \\
& I & No & 642 & 78.37 \\
Used condom at last intercourse & 2 & Yes & 177 & 21.63 \\
& I & No & 54 & 6.62 \\
Less than four lifetime of sexual partners & 2 & Yes & 765 & 93.38 \\
No alcohol consumption last time had sex & I & No & 44 & 5.4
\end{tabular}


African Population Studies Vol. 29, No. 2, Supplement, 2015

\begin{tabular}{lrlll}
\hline Variable & Code & Label & Frequency & Percent \\
\hline Indicators of latent class & & & & \\
Categorical covariate & 2 & Yes & 775 & 94.6 \\
Education & & & & \\
& 0 & CSecondary & 146 & 17.81 \\
Religion & I & Secondary+ & 673 & 82.19 \\
& 1 & Christian & 690 & 84.2 \\
& 2 & Muslim & 103 & 12.53 \\
Type of place of residence & 3 & Other & 27 & 3.27 \\
& 0 & Urban & 512 & 62.45 \\
Economic status & I & Rural & 308 & 37.55 \\
& 0 & Earning wages & 430 & 52.46 \\
Continues covariate & I & Not earning wages & 389 & 47.54 \\
Age & Mean & Std. Dev. & & \\
Average knowledge of HIV prevention & 22.1 I & 4.97 & & \\
\hline Total (Weighted) & 2.46 & 0.80 & & \\
\hline
\end{tabular}

\section{Model selection}

LCA was applied (Collison \& Lanza, 2010; McCutcheon, 1987) to assess the pattern typologies of risky sexual behaviours among sexually active never married Ghanaian women. A model with two latent classes was first examined, three latent classes, and so on. How well each model fit the data were examined based on the $G^{2}$ statistic, degrees of freedom as well as the information criteria (AIC, BIC, CAIC and $a B I C)$. The fall in $G^{2}$ in relation to the fall in degrees of freedom is considerable with every additional class up to the 5 -class model. However, comparing models 3, 4 and 5 with regard to the AIC and BIC figures (Table 2) indicates that the 3-class model is the best-fit model among the models. In addition, in selecting the final model, it is important to take into consideration the interpretation of the classes of the selected model. In essence, whether the latent categories in a solution showed intuitive patterns, were different from the other categories and could easily be labelled (Lanza et al., 2007; Lanza \& Rhoades, 20I3).

Table 2 Indicators of fit for models with two through five latent classes

\begin{tabular}{lllllll}
\hline Number of classes & $\mathrm{df}$ & $\mathrm{G}^{2}$ & $\mathrm{AIC}$ & $\mathrm{BIC}$ & $\mathrm{CAIC}$ & $\mathrm{aBIC}$ \\
\hline 2 & 50 & 61.8 & 87.8 & 148.3 & 161.3 & 107.0 \\
3 & 43 & 19.4 & 59.4 & 152.4 & 172.4 & 88.9 \\
4 & 36 & 15.1 & 69.1 & 194.8 & 221.8 & 109.0 \\
5 & 29 & 11.7 & 79.7 & 237.9 & 271.9 & 129.9 \\
\hline
\end{tabular}


Latent class probabilities and item response probabilities

Table 3 shows the estimated marginal and conditional probabilities by class. The marginal probability for Class $\mathrm{I}$ is 0.20 $(20 \%)$, meaning that the proportion of women classified into Class I were $20 \%$ of the sample. The proportion of women classified into Classes 2 and 3 are 58\% $(0.58)$ and $23 \%(0.23)$ respectively.

A general look at the conditional probabilities of the risky sexual behaviour patterns of the women shows that women classified in Class I relatively engaged in less risky sexual behaviours compared to women in Class 2 and 3. Thirteen percent of women in Class I engaged in sexual intercourse before age 16 and $34 \%$ of them did not use a condom at first sexual intercourse. Further, all of them (100\%) had sexual intercourse with another person other than their partners in the last 12 months; however, only II\% of them did not use a condom at last sexual intercourse. Four percent of them had more than three lifetime sexual partners and none of them used alcohol at last sexual intercourse. Thus, Class I is labelled as "low risk takers" group.

Class 2 is labelled as "risk takers" group because $23 \%$ engaged in sexual intercourse before age 16. However, 53\% (relatively lower compared to Class I and 3) had sexual intercourse with another person(s) other than their partners in the last 12 months. In Class 2, two percent of the women had more than three lifetime sexual partners and none of them consumed alcohol at last sexual intercourse. Nevertheless, $84 \%$ of them did not use condom at first sexual intercourse and $100 \%$ of them had unprotected sex during their last sexual encounter.

Class 3 is labelled as "high risk takers" group. The probability of engaging in risky sexual behaviours was in most cases relatively high in this class compared to Class I and 2. A little more than a fifth (22\%) of the women in Class 3 had their first sexual intercourse before age 16 and all of them (100\%) had sexual intercourse with another person(s) other than their partners in the last 12 months. Moreover, a higher percentage $(86 \%)$ of them had unprotected sex at their first sexual encounter and about eight out of ten (78\%) of them had unprotected sex at last sexual intercourse. About two in ten $(20 \%)$ of them had more than three lifetime sexual partners and about the same proportion $(21 \%)$ consumed alcohol at last sexual intercourse. 
Table 3: Latent class marginal and conditional probabilities for the women's sexual behaviours

\begin{tabular}{lccc}
\hline & $\begin{array}{c}\text { Class I- } \\
\text { "Low risk } \\
\text { takers" }\end{array}$ & $\begin{array}{c}\text { Class 2-“Risk } \\
\text { takers" }\end{array}$ & $\begin{array}{c}\text { Class 3-“High risk } \\
\text { takers" }\end{array}$ \\
\hline Marginal probability & 0.20 & 0.58 & 0.23
\end{tabular}

Conditional probability

Sexual intercourse after age 16

$\begin{array}{llll}\text { No } & 0.13 & 0.23 & 0.22 \\ \text { Yes } & 0.87 & 0.77 & 0.78\end{array}$

Sexual intercourse with only partner in the last 12 months

$\begin{array}{llll}\text { No } & 1.00 & 0.53 & 1.00 \\ \text { Yes } & 0.00 & 0.47 & 0.00\end{array}$

Condom used at first sexual

intercourse

$\begin{array}{llll}\text { No } & 0.34 & 0.84 & 0.86 \\ \text { Yes } & 0.66 & 0.16 & 0.14\end{array}$

Used condom at last sexual intercourse

$\begin{array}{llll}\text { No } & 0.11 & 1.00 & 0.78 \\ \text { Yes } & 0.89 & 0.00 & 0.22\end{array}$

Less than three lifetime number of sexual partners

$\begin{array}{llll}\text { No } & 0.04 & 0.02 & 0.20 \\ \text { Yes } & 0.96 & 0.98 & 0.80\end{array}$

No alcohol consumption last time had sex
No
0.00
0.00
0.21
Yes
1.00
1.00
0.79

Latent class membership prediction

Table 4 shows the odds ratios and Confidence Intervals (Cls) of a latent multinomial logistic regression model results. It is important to note that a covariate is significantly related with an increase or decrease in odds of http://aps.journals.ac.za membership in a particular latent class in relation to the reference latent class corresponding to a different level on the covariate, when the $95 \%$ Confidence Interval for the odds ratio does not comprise of the figure 1.0 (Lanza \& Rhoades, 2013). The reference group for 
the latent multinomial regression model was the "low risk takers" (Class I) class. Age appeared to be the only variable significantly predicting membership in both the "risk takers" (Class 2) and the "high risk takers" (Class 3) classes compared to being in "low risk takers" class.

Holding all other variables constant, age is significantly related to the likelihood of being classified in the "risk takers" (Class 2) class (OR $=3.97, \mathrm{Cl}=2.6 \mathrm{I}, 6.05)$ versus being classified in the "low risk takers" class. A unit increase in age, increases the odds of being classified in the "risk takers" class relative to being classified in the "low risk takers" class by 3.97 times.

Regarding Class 3 ("high risk takers"), age again has a significant effect on the likelihood of being classified in the "high risk takers" class relative to being classified in the "low risk takers" class. The results show that an increase in age increases the odds of being classified into the "high risk takers" class relative to being classified in the "low risk takers" class by 3.56 times $(\mathrm{Cl}$ $=2.31,5.94$ ).

\section{Table 4: Results of latent multinomial logistic regression model}

\begin{tabular}{|c|c|c|c|}
\hline Variable & $\begin{array}{c}\text { Class I-“Low risk } \\
\text { takers” }\end{array}$ & $\begin{array}{l}\text { Class 2-“Risk } \\
\text { takers” }\end{array}$ & $\begin{array}{c}\text { Class 3-“High risk } \\
\text { takers” }\end{array}$ \\
\hline Age & - & $\begin{array}{c}3.97 \\
(2.61,6.05)\end{array}$ & $\begin{array}{c}3.56 \\
(2.31,5.49)\end{array}$ \\
\hline $\begin{array}{l}\text { Education } \\
\quad<\text { Secondary (ref.) }\end{array}$ & & & \\
\hline Secondary+ & - & $\begin{array}{c}1.21 \\
(0.31,4.78)\end{array}$ & $\begin{array}{c}2.60 \\
(0.51,13.31)\end{array}$ \\
\hline $\begin{array}{l}\text { Religion } \\
\text { Christian (ref.) }\end{array}$ & & & \\
\hline Muslim & - & $\begin{array}{c}1.05 \\
(0.37,3.02)\end{array}$ & $\begin{array}{c}1.10 \\
(0.34,3.57)\end{array}$ \\
\hline Other & - & $\begin{array}{c}2.91 \\
(0.43,19.57)\end{array}$ & $\begin{array}{c}1.47 \\
(0.20,11.02)\end{array}$ \\
\hline $\begin{array}{l}\text { Residence } \\
\text { Urban (ref.) }\end{array}$ & & & \\
\hline Rural & - & $\begin{array}{c}0.91 \\
(0.33,2.47)\end{array}$ & $\begin{array}{c}0.69 \\
(0.25,1.93)\end{array}$ \\
\hline $\begin{array}{l}\text { Economic status } \\
\text { Earn wages (ref.) }\end{array}$ & & & \\
\hline Do not earn wages & - & $\begin{array}{c}2.43 \\
(0.83,7.09)\end{array}$ & $\begin{array}{c}1.52 \\
(0.53,4.33)\end{array}$ \\
\hline $\begin{array}{l}\text { Knowledge of HIV } \\
\text { transmission }\end{array}$ & - & $\begin{array}{c}1.83 \\
(0.99,3.38)\end{array}$ & $\begin{array}{c}1.74 \\
(0.90,3.34)\end{array}$ \\
\hline
\end{tabular}

Values in parenthesis ( ) are $95 \%$ confidence intervals 


\section{Class membership association}

Table 5 shows class membership associations between individual characteristics by class. A significant association was found between the classes and all factors except religion. In Table 5, the latent class membership used for the bivariate analysis with the covariates was exported from the LCA modelling to perform this procedure. The proportion of those with below secondary education was found to be highest $(29.62 \%)$ in Class I ("low risk takers"), followed by Class 2 (19.47\%), and class 3 (7.7I\%) ("high risk takers"). On the other hand, the proportion of those with secondary education or higher was highest in Class 3 ("high risk takers") and lowest (70.38\%) in Class I ("Low risk takers"). While the highest percentage $(85.88 \%)$ of Christians were in Class 3 ("high risk takers"), the highest proportion of Muslim women
(13.96\%) and women affiliated to the group of other religions $(4.00 \%)$ were highest in Class I ("low risk takers"). Whereas a higher proportion $(72.59 \%)$ of urban women were in Class 3 ("high risk takers"), a higher proportion (46.56\%) of rural women were in Class I ("low risk takers"). Women earning wages were found to be highest $(57.10 \%)$ in Class 2 ("risk takers") and women not engaged in wage earning labour were found to be highest (74.30\%) in Class I ("low risk takers"). Women in Class I ("low risk takers") were younger (mean $=17$ years old) than women in the "risk takers" class (mean $=23$ years) and the "high risk takers" class (mean $=22$ years). Contrary to expectation, the average knowledge of HIV prevention was lowest in Class I (mean $=2.29$ ), the "low risk takers" compared to the other classes.

Table 5: Observed individual characteristics by latent class

\begin{tabular}{lrrrr}
\hline Variable & $\begin{array}{c}\text { Class I-“Low risk } \\
\text { takers” }\end{array}$ & $\begin{array}{c}\text { Class 2-“Risk } \\
\text { takers” }\end{array}$ & $\begin{array}{c}\text { Class 3-“High risk } \\
\text { takers” }\end{array}$ \\
\hline Education & 29.62 & 19.47 & $23.00^{* * * *}$ & 7.71 \\
$\quad$ SSecondary & 70.38 & 80.53 & & 92.29 \\
$\quad$ Secondary+ & 2.5 & & & \\
Religion & 82.04 & 83.97 & & 85.88 \\
$\quad$ Christian & 13.96 & 12.25 & & 12.54 \\
$\quad$ Muslim & 4.00 & 3.78 & $12.55^{* * *}$ & 1.58 \\
$\quad$ Other & & & & 72.59 \\
Residence & 53.44 & 60.25 & & 27.41 \\
$\quad$ Urban & 46.56 & 39.75 & $31.04^{* * * *}$ & \\
$\quad$ Rural & & & & 53.55 \\
Economic status & 25.70 & 57.10 & & 46.45 \\
$\quad$ Earn wages & 74.30 & 42.90 & & 21.68 \\
$\quad$ Do not earn wages & & & & 3.53 \\
Continuous variables & 16.76 & 23.29 & & \\
Mean age & 1.23 & 5.19 & $15.33^{* * * *}$ & \\
$\quad$ Std. Dev. & & & &
\end{tabular}




\begin{tabular}{|c|c|c|c|}
\hline Variable & $\begin{array}{c}\text { Class I-“Low risk } \\
\text { takers” }\end{array}$ & $\begin{array}{c}\text { Class 2-“Risk } \\
\text { takers” }\end{array}$ & $\begin{array}{c}\text { Class 3-“High risk } \\
\text { takers” }\end{array}$ \\
\hline $\begin{array}{l}\text { Average knowledge of HIV } \\
\text { prevention }\end{array}$ & 2.29 & 2.48 & 2.49 \\
\hline $\begin{array}{l}\text { Std. Dev. } \\
\text { F-test }\end{array}$ & 0.96 & 0.76 & $2.33^{+}$ \\
\hline Total (Weighted) & 98 & 520 & 200 \\
\hline
\end{tabular}

\section{Discussion}

This study sought to categorise sexually active never married Ghanaian women based on their sexual behaviours in order to describe and analyse their risky sexual behaviour patterns. A 3-class solution appeared to be reflective of the different subgroups of sexually active never married Ghanaian women based on their risky sexual behaviour patterns. A higher proportion $(58.00 \%)$ of the sexually active never married Ghanaian women appeared to be classified in the "risk takers" class (Class 2), followed by Class 3 the "high risk takers" (23.00\%) and Class I the "low risk takers" (20.00\%).

A study in the USA that also utilised LCA to examine sexual risk behaviour among adolescents found that a 4-class solution was reflective of the different subgroups of sexual risk behaviours ("abstainers", "monogamous", "low-frequency multipartner" and "high-frequency multipartner"). Of the four classes, the highest proportion of the adolescents were classified as abstainers (53.00\%) (Connell et al., 2009), in the present study however, the highest proportion of women were classified into the "risk takers" (58.00\%) class. Indeed, the different target populations could explain the differences between these classifications as well as the differences in the indicators of risky sexual behaviour utilised in the LCA modelling.

The "high risk takers" class (Class 3) was a group where the probability of having sex before age 16 was relatively high and at that time a condom was not used. Indeed, at last sexual intercourse the probability of them using a condom was still very low even though they engaged in sexual activity with multiple sexual partners in the last 12 months and had more than three lifetime sexual partners. Over and above, it was only in the "high risk takers" class (Class 3) that alcohol was consumed during last sexual intercourse. Recent evidence on risky sexual behaviours in the Ghanaian context show that the proportion of young women who had sex in the last one month was $76 \%$, those who had unprotected sex at last sexual activity was $80 \%$ and those who had multiple sexual partners was 60 percent (Asante et al., 20|4). This perhaps lends credence to the low proportion of sexually active never married women being classified in the "low risk takers" class.

Some studies on risky sexual behaviours among adolescents show that age is not significantly related to risky sexual behaviour (Madise et al., 2007). Madise et al. (2007) found that age was not 
significantly related to age at first sexual encounter, condom use with the most recent sexual partner and number of sexual partners. However, in the present paper, age was the most important factor that predicted class membership, showing that older women were more likely to be classified in to the "high risk takers" class. Perhaps the differences in the two studies are due to the different target populations and statistical approaches adopted. Nevertheless, the plausible explanation for the results of the present study is the fact that older sexually active women who have never married are more likely not to be under parental control and for that matter are more likely to indulge in risky sexual behaviour. This explanation also falls in line with the characteristics of the sexually active never married women classified in that class. Because these women (Class 3"high risk takers") were on average relatively older women (mean age $=22$ ), had secondary or higher education, in urban areas and also earned wages, they were more exposed and also had the freedom to indulge in risky sexual behaviours.

Class 2 ("risk takers") was a group where the probability of having sex before age 16 was highest $(0.23)$. The probability of not using a condom at first sexual intercourse was also very high (0.84) and indeed, none of them used a condom at last sexual intercourse. Perhaps what makes this group look like they are cautious risk takers relative to the "high risk takers" is that, even though they appeared not to be using condoms, the probability of them having multiple sexual partners in the last 12 months was relatively lower compared to Class I ("low risk takers") and Class 3 ("high risk takers"). In addition, they did not consume alcohol at their last sexual intercourse unlike women classified in the "high risk takers" class (Class 3). Age was an important factor that predicted class membership in this group. Women who were older were more likely to be classified in the "risk takers" class (Class 2) relative to being classified in "low risk takers" class (Class I). This group ("risk takers") was characterised by relatively older women (mean age $=23$ ) and mostly Christian. In addition, they were residing in urban areas and earning wages.

These findings have implications for policy makers targeting safe sex practices among sexually active never married Ghanaian women. The results of the present study suggest that interventions targeting sexually active never married women will have to tackle a broad range of risky sexual behaviours. In addition, different targeted interventions might be desirable for the various subgroups "low risk takers", "risk takers" and "high risk takers".

\section{References}

Akwara, P., Fosu, G., Govindasamy, P., Alayón, S., \& Hyslop, A. 2005. An indepth analysis of HIV prevalence in Ghana: further analysis of Demographic and Health Surveys data. Calverton, USA: ORC Marco, Measure DHS. Retrieved from http://www.popline.org/node/2570I 2 Asante, K., Meyer-Weitz, A., \& Petersen, I. 2014. Substance use and risky sexual behaviours among street connected children and youth in Accra, Ghana. 
Substance Abuse Treatment, Prevention, and Policy, 9(45): I-9.

Bongaarts, J. (2007). Late marriage and the HIV epidemic in sub-Saharan Africa. Population Studies, 6I(I): 73-83. http://doi.org/I0.1080/0032472060104 8343

Chao, A., Bulterys, M., Musanganire, F., Abimana, P., Nawrocki, P., Taylor, E., ... Team, T. N. U. of R.-J. H. U. A. R. 1994. Risk Factors Associated with Prevalent HIV-I Infection among Pregnant Women in Rwanda. International Journal of Epidemiology, 23(2):

$37 \mid-380$. http://doi.org//0.1093/ije/23.2.37I

Collison, L. M., \& Lanza, S. T. 20I0. Latent class and latent transition analysis: With applications in the social, behavioural, and health science. New York: Wiley.

Connell, C. M., Gilreath, T. D., \& Hansen, N. B. 2009. A Multiprocess Latent Class Analysis of the Co-Occurrence of Substance Use and Sexual Risk Behavior Among Adolescents. Journal of Studies on Alcohol and Drugs, 70(6): 943-95I.

Dewilde, C. 2004. The Multidimensional Measurement of Poverty in Belgium and Britain: A Categorical Approach. Social Indicators Research, 68(3): $331-$ 369.

http://doi.org// 0.1023/B:SOCl.000003 3578.81639.89

Doku, D. 2012. Substance use and risky sexual behaviours among sexually experienced Ghanaian youth. BMC Public Health, 12(I): 57I. http://doi.org/I0.I I86/I47|-2458-I2571

Ghana Statistical Service, Ghana Health Service, \& ICF Macro. 2009. Ghana Demographic and Health Survey 2008.
Accra, Ghana: GSS, GHS, and ICF Macro.

Halpern-Felsher, B. L., Millstein, S. G., \& Ellen, J. M. 1996. Relationship of alcohol use and risky sexual behavior: A review and analysis of findings. Journal of Adolescent Health, 19(5): 33I-336. http://doi.org/10.1016/S1054-

I39X(96)00024-9

Karim, A. M., Magnani, R. J., Morgan, G. T., \& Bond, K. C. 2003. Reproductive Health Risk and Protective Factors among Unmarried Youth in Ghana. International Family Planning Perspectives, 29(I): 14-24. http://doi.org//0.2307/3180997

Lanza, S. T., Collins, L. M., Lemmon, D. R., \& Schafer, J. L. 2007. PROC LCA: A SAS Procedure for Latent Class Analysis. Structural Equation Modeling: A Multidisciplinary Journal, I4(4): 67I694.

http://doi.org//0.1080/107055/070I57 5602

Lanza, S. T., Dziak, J. J., Huang, L., Wagner, A. T., \& Collison, L. M. 20I5. LCA Stata Plugin Users' Guide (Version I.2). University Park: The Methodology Center, Penn State.

Lanza, S. T., \& Rhoades, B. L. 2013. Latent Class Analysis: An Alternative Perspective on Subgroup Analysis in Prevention and Treatment. Prevention Science, 14(2): 157-168. http://doi.org/|0.1007/s | | | 2I-0| I0201-I

Madise, N., Zulu, E., \& Ciera, J. 2007. Is poverty a driver for risky sexual behaviour? Evidence from national surveys of adolescents in four African countries: original research article. Retrieved from 
African Population Studies Vol. 29, No. 2, Supplement, 2015

http://reference.sabinet.co.za/sa_epubl ication_article/ajrh_vl I_n3_a7

McCutcheon, A. L. 1987. Latent Class Analysis. Newbury Park, CA: SAGE.

Mturi, A. J., \& Gaearwe, L. 2014. Gender differences in sexual behaviour amongst university students in Mahikeng, South Africa. African Population Studies, 20(I): 526-537.

Nunn, A., Kengeya-Kayondo, J., Malamba, S., Seeley, J., \& Mulder, D. 1994. Risk factors for HIV-I infection in adults in a rural Ugandan community: a population study. AIDS, 8: 8I-86.

Sachdeva, R., \& Wanchu, A. 2006. Women's issues in HIV infection. JK Science, 8(3): 129-132.

Wojcicki, J. 2005. Socioeconomic status as a risk factor for HIV infection in women in East, Central and Southern Africa: A systematic review. Journal of Biosocial Science, 37(I): I-36. 